\title{
Grasping political cartoons? Not an easy matter
}

\author{
Dafina Genova \\ University of Veliko Tarnovo St. Cyril and St. Methodius, Bulgaria \\ dafiangenova50@gmail.com
}

\begin{abstract}
The article focuses on the interpretation of political cartoons and the means of expression a cartoonist uses to convey a message: visual metaphors, visual metonymies as well as metaphors inferred from the image and/or text. The metaphors and visual metonymies in the cartoons are analyzed from the point of view of Conceptual Metaphor and Metonymy Theory. In the analysis, visual and inferential metaphors are viewed as incongruities; there are also incongruities as a result of the interaction between image, title and/or caption. Political cartoons can have more than one focal (visual) incongruity that enables the introduction of a Logical Mechanism from the General Theory of Verbal Humour (GTVH) to (partially) resolve the incongruity/ies. Visual metonymies and images can also function as enablers of a Logical Mechanism. Image and/or text can contrast with or reinforce a Logical Mechanism. Additionally, visual metaphors and metonymies function as contextualization indexes in the interpretation of the cartoons. Humour is the means to get the cartoonist's message across to the viewer/reader and not an end in itself.
\end{abstract}

Keywords: humour, political cartoons, incongruity, visual incongruity, visual metaphor, visual metonymy.

\section{Introduction}

As a form of communication, the humorous mode is grounded in the serious; the former constantly makes explicit and implicit references to the latter and in this respect the humorous mode of communication is less autonomous compared to the serious mode. As stated elsewhere (Genova 2011), humour in jokes has to be simultaneously analysed from three different perspectives as a theoretical minimum: cognitive, social and linguistic - from the cognitive to the linguistic and then to the social context. From a cognitive perspective, humour is analysed through the concept of incongruity and its resolution (Suls 1972; Suls 1983; Schultz 1976) or its partial resolution (McGhee et al. 1990, Attardo 1997, Hempelmann and Attardo 2011). From a social point of view, humour is the result of the transgression of a social norm or convention (Kuipers 2006). Sociological approaches to the analysis of humour in jokes focus on the motivation of the joke teller and the listener's response to the humour in the joke text rather than the incongruity itself as its defining cognitive and textual structure 
feature. Incongruity in the joke text is a prerequisite for humour and it might or might not be supplemented by a transgression of a norm. As far as language is concerned, it is only the means to express humour, but not the cause for humour.

The article focuses on incongruities in political cartoons-visual metaphors, inferential metaphors and incongruities arising from the interaction between pictorial representation and text. The metaphors and visual metonymies in the cartoons are analysed from the point of view of Conceptual Metaphor and Metonymy Theory. Visual metaphors, inferential metaphors and visual metonymies evoke or contribute to the evocation of a Logical Mechanism from the GTVH to (partially) resolve the incongruities. Additionally, metaphors and visual metonymies function as contextualization indexes in cartoon interpretation.

Proponents of the GTVH hold the view that incongruity and script opposition and overlap conceptualize differently the same phenomenon (Attardo 1997: 401) or that the former corresponds to the latter (Attardo et al. 2002: 5). They go even further in claiming that there is an equation between the two (Hempelmann and Attardo 2011: 130), hence the use of incongruity in this article and not script opposition and overlap. In the analysis, incongruity in its broad sense - a high degree of contrast and a low degree of similarity between scripts with jokes - is extended to domains in verbal and visual metaphors. The proponents of the GTVH also hold the view that the parameter Logical Mechanism from the theory corresponds to incongruity-resolution in the Incongruity Theory of Humour (Suls 1972, 1983; Shultz 1976), but the resolution is never fully resolved, it is essentially partial (Attardo 1997, Attardo et al. 2002, Hempelmann \& Attardo 2011: 130).

The speculation that verbal metaphor is an instantiation of incongruity is not new in the literature (Kittay 1990: 81; Oring 2003: 5; Steen 2007: 280). For Oring the incongruity in metaphor is "genuine" (not funny), while in jokes it is "spurious", that is, funny. It seems reasonable to take into account the specificity of the medium in which humour occurs. Oring might be right about verbal metaphors, in which we have mapping of behavioural features onto personality traits as in, for example, Man is a wolf, ergo, conceptual congruence, yet in the corresponding visual metaphor of a man with a wolf's head or a wolf's body with a man's head there is hardly any visual congruence. Incongruity is the prerequisite for humour, but a Logical Mechanism from the GTVH is needed to make sense of the nonsense. The interpreter rather laughs at the (partial) resolution of the incongruity and not at the incongruity itself.

For the purposes of the present article, it is necessary to distinguish caricatures from cartoons, editorial political cartoons and comics. A (portrait) caricature is a pictorial representation of a political or public figure whose physical features are distorted or exaggerated with the intention to capture character. Cartoons also make use of the same drawing/painting styles, but in addition they contain at least one incongruity (Hempelmann \& Sampson 2008: 615). And in this respect they are identical to jokes, that is, cartoons are jokes told in a drawing or painting (Nilsen \& Nilsen 2000). Yet cartoons (e.g., Gary Larson's) and political cartoons differ in their communicative goal: in cartoons (and in prototypical jokes) the main objective is to amuse through humour in the punchline, while in political cartoons cartoonists claim their goal is to make a political or moral point and humour is the means to get their message across: "Editorial cartoons can be funny, but more importantly, cartoons are a reflection of ourselves, our feelings and our reactions to the news of the day-a reflection that gives us a better view of who we're and how we felt as history happened" (Cagle \& Fairrington 2007: VI). Cartoons and jokes expect us to laugh, while political cartoons expect us to think on an issue. It does not mean that jokes are incapable of passing on serious messages, e.g., underground political jokes in totalitarian and authoritarian states, which as a joke type stand closest to the serious mode of communication compared to nonsense jokes situated at the opposite end of the joke scale. Humour in political cartoons, when they are funny and not serious, is qualitatively different from humour in cartoons: it targets politicians 
and its intent is not to amuse, but mock and ridicule the powerful. On the other hand, in addition to incongruities, what cartoons and political cartoons have in common, are visual metaphors and metonymies - an indispensable means of expression for both. As far as comics go, they tell stories, their drawings are more detailed and they are more authentic in representing reality.

\section{Communicative goal of political cartoons and means of expression}

A (political) cartoon is a hybrid of pictorial representations, verbal text, symbols, shadings and humour. Written comments and humour in political cartoons are optional and cartoonists employ the other 'ingredients' of cartoons to a varied degree. The pictorial representation is a compressed text that is, by presumption, not as cohesive and coherent as its verbal counterpart with an analogous topic of discourse. Additionally, the former is open to more interpretations than the latter. A marked difference between a written text and a political cartoon is that the latter is not suitable for the presentation of consecutive events, although two- and three-panel political cartoons can achieve temporal consecutiveness up to a point. Abstract concepts in (political) cartoons are expressed through metaphor, metonymy or symbol (El Refaie 2014). In the interpretation of political cartoons the viewer/reader constantly alternates between the visual and verbal mode of communication, each changing from figure to ground supporting or adding information to the other.

Political cartoons address newspaper readers (and recently TV and internet viewers) and often the recognition of the images of political and public figures in the cartoons requires extensive background knowledge of current events and politicians' comments on the events on the part of the interpreter. In other words, the viewer is expected to be as well-informed and educated (especially when intertextuality is used as a communicative strategy in the pictorial representation) as the political cartoonist himself/herself. But is it always the case? Pat Oliphant - an Australian editorial cartoonist, whose career spans more than fifty years, says:

You have to have a frame of reference to appreciate a cartoon, to know what is being caricatured. People don't do the reading of news anymore that would give them the background to know what the cartoon is about; you can't refer to accepted wisdom or variations of accepted wisdom. We are in a forest fire of ignorance. ${ }^{1}$

Very often, additional background reading is needed to interpret political cartoons of past events when political cartoons are uploaded on the internet or when they are used, e.g., as a tool in teaching history in the classroom. To overcome this difficulty, collections of political cartoons give information under each cartoon about the politicians and the event represented in the cartoon as well as the cartoonist's comments about his/her motivation in drawing/painting the cartoon. Television and internet have worsened the situation: they have considerably reduced the number of appreciators of political cartoons whose locus, traditionally, has been the print media.

In addition to the viewer's/reader's knowledge of current events and news, the interpretation of political cartoons is dependent on the extent to which the pictorial representation deviates from his/her knowledge of the world as well as on his/her familiarity with the genre. The interpretation usually involves three cognitive processes: 1) recognition of the images, 2) working out the issue or event they evoke from reality and 3) getting the cartoonist's message. Recognition and comprehension may or may not be followed by appreciation of a political cartoon, that is, laughter. In cases when recognition and comprehension demand a higher cognitive effort, the effort has a negative effect on the appreciation. Although pictures and images are processed and remembered more easily than 
words (Grady et al. 1998), the perception of visual metaphors and metonymies in political cartoons included, it is the verbal 'translation' of the images or their 'rationalization' that might cause comprehension challenges. And the 'translation' is not always the viewer's fault — not having enough background knowledge of current events and news, but the fact that not "every visual form has an exact verbal equivalent" (El Refaie 2003: 90) in the sense it is easy to say in words what is seen in the cartoon, but not easy to construct a coherent text about what is meant by it, sometimes even impossible, when the pictorial representation deviates too much from what we know about the world. And if this is right, no full comprehension is possible of, at least, some (political) cartoons. Punchlines in jokes might also be difficult to comprehend, yet it goes without saying that jokes are more widely appreciated compared to cartoons and political cartoons.

As already mentioned, getting the cartoonist's message and his/her communicative goal is the final component in the comprehension of political cartoons. The political cartoonist aims at focusing the public attention on a political or social issue or injustice. Or he/she aims at making a moral judgment. The highest a political cartoonist aims at is bringing about a change in the viewer's opinion on an issue. In other words, political cartoons have a layer of meaning that is reserved for conveying serious messages as in some forms of standup comedy, for example, George Carlin's or the TV shows The Daily Show and The Colbert Report, hosted by Jon Stewart and Stephen Colbert: they aimed at uncovering hypocrisy, absurdities and hidden truths. Those messages are indeterminate and open-ended, yet there are there for the viewer/reader to get and ponder upon. Political cartoonists often say they work in the borderline area between art and journalism. According to Martin Rowson, whose cartoons appear regularly in The Guardian, The Scotsman, The Mirror and The Tribune, “...cartoonists are journalistic chimeras: how they think, what they express and its effect on the readers makes them much more like columnists than illustrators, and personally I see myself as a visual journalist rather than as any kind of 'artist'". ${ }^{2}$

As mentioned at the beginning, political cartoonists hold the view that humour in political cartoons is not their main objective. Instead, political cartoons aim at political and social commentary and critique. According to newspaper editor Patrick Powell, the main communicative goal of a political cartoon is "to make a point succinctly and memorably... Certainly, if a political cartoon does raise a laugh by, e.g., portraying a politician or a situation as ridiculous, that's a bonus." ${ }^{3}$ There seems to be a gap between practice and theory: humourists hold the view that humour in political cartoons is a "bonus", while humour theorists do not differentiate between humour in cartoons and political cartoons, so they implicitly suggest, contrary to humourists, that political cartoons are funny by presumption (Sampson \& Huber 2007, Hempelmann \& Sampson 2008, Tsakona 2009). Following Sampson \& Huber (2007), in cartoons (and for the author in political cartoons) there are three loci for incongruity: in the pictorial representation, in the interaction between representation and text and in the text, when there is text.

As already stated, visual metaphors and metonymies are an indispensable means of expression in political cartoons. In a number of studies, visual metaphors in political cartoons have been analysed in comparison to verbal metaphors. The studies adopt a cognitive perspective on the issue: metaphor is not a linguistic phenomenon, it is a way of thinking and, more specifically, it is the comprehension of one concept in terms of another. In her account of Austrian political cartoons, El Refaie (2003) reduces a visual metaphor to a verbal nominal metaphor that is of the form 'A is B', using the topic-and-vehicle metaphor model instead of the currently prevalent target-and-source model (Lakoff \& Johnson 1980, Lakoff 1987). El Refaie's understanding of visual metaphor is wider that the traditional one: according to the traditional view (Gombrich 1971), a visual metaphor in political cartoons is a fusion of parts from disparate areas of experience, e.g., the face of a politician with the body of an animal or 
the other way round. El Refaie argues such a definition is too narrow because in visual metaphors either the vehicle or, more frequently, the topic is not shown in the pictorial representation (El Refaie 2003), unlike verbal metaphors, in which both are present. El Refaie follows Kennedy et al.'s claim (1993) that any visual depiction is a metaphor "provided that its use is intended to occasion a metaphoric thought" (Kennedy et al. 1993, quoted in El Refaie 2003: 80). There is a notable difference between visual and nominal verbal metaphors: the former connect two concrete objects, whereas with nominal verbal metaphors the target domain is usually more abstract than the source domain (El Refaie 2014). Forceville (2002) has studied explicitly and implicitly signalled cinematic metaphors and their target and source structure. For him, the irreversibility of the target and source domain is one of the defining features of a prototypical verbal and visual metaphor although reversibility is not excluded (compare KNOWING IS SEEING and SEEING IS KNOWING). To repeat, in the present analysis of political cartoons, the incongruity between the focus/target and the frame/source in verbal metaphors (Kittay 1990: 81) is extended to visual metaphors (Forceville 2002: 4). In addition to the visual incongruities in the images, there could be incongruities between images on the one hand and title and captions on the other, as well as inferential incongruities in the form of conceptual metaphors beyond images, title and captions the interpreter gets to to fully interpret a (political) cartoon. Visual metaphors in political cartoons do not always express a novel metaphorical thought: often enough they are direct pictorial representations of conventional verbal metaphors. It is worth noting that there is a substantial difference between the nominal metaphor Peter is a pig and its visual expression, e.g., Peter's body with a pig's head, or, alternatively, a pig's body with Peter's head or face: in visual metaphors, when both the target and the source are present in the pictorial representation, there is a fusion of two concepts unlike verbal metaphors, in which one concept is understood in terms of another. Fusion in the sense of a single image: simultaneously, the two entities - man and pig - are visually opposed, that is, no blended visual image of the two entities is possible.

An overview of the studies on (political) cartoons shows that researchers either analyse the visual metaphors or the humour in them but not both and the first type of studies is more numerous than the second. In her account of humour in political cartoons, Tsakona (2009) makes use of the GTVH (Attardo \& Raskin 1991; Attardo 2001; Hempelmann \& Attardo 2011), a broad theory that includes a semantic and a pragmatic analysis of humour with its six parameters or knowledge resources: Script Opposition, Logical Mechanism, Situation, Target, Narrative Strategy and Language. The two instances of visual metaphor in the political cartoons Tsakona analyses are subsumed under the parameter Language together with parallel verbal metaphors. Since verbal and visual metaphors correspond to the notion of incongruity, they are to be incorporated not in the Language, but in the Script Opposition parameter of the GTVH. Another reason can be pointed out for such a consideration: the fact that there is not a one-to-one correspondence between non-verbal and verbal communication, e.g., for Peter is a pig, as stated earlier, there would be two images-Peter's body with a pig's head or a pig's body with Peter's head or face. Tsakona acknowledges the presence of more than one incongruity in political cartoons, but in her analysis she has chosen to analyse cartoons in which there is only one. The Logical Mechanisms in political cartoons are expected to be the same as the ones used in jokes: in Tsakona's study they are exaggeration, role reversal, analogy and juxtaposition.

\section{Incongruities in political cartoons}

About 200 political cartoons from the internet were studied and only 8 were selected for analysis. In the article, the cartoons are laid out in terms of the extent to which the pictorial 
representation deviates from our knowledge of the world. The first things the interpreter wants to know is what the cartoon is about as well as the single statement, an opinion or a judgment on an event or issue the cartoonist has in mind that he/she 'translates' into a pictorial representation: e.g., David Cameron's and Nigel Farage's position to job seekers from EU member states from Eastern Europe or UK after Brexit in the analysed political cartoons below. Sometimes the statement can be verbally expressed in the title or cartoon(s). The statement might as well be the title of a newspaper editorial. But the rest of the interpretation of a political cartoon is often a puzzle; as a result, its interpretation is fragmentary and associative.

The first cartoon is entitled What We Bring to Afghanistan and is about Britain's involvement in the conflict in Afghanistan. It is by Peter Brookes ${ }^{4}$ and is published in the Independent, September 9, 2009.

Visual and verbal context in the cartoon. It is not separated by lines into four panels, but it is perceived as a four-panel one. In the first section we see an Afghan man dressed in a traditional costume, a turban on his head and many ballot papers sticking out of his right pocket. With his hands he is trying to get as many ballot papers as possible into a transparent ballot box. Below the section in large letters is the caption Democracy... In the section to the right, we see a big black hole in the ground, men lying around and perceived as casualties, and a plane in the sky. Below the section, again in large letters, is the caption Security... In the third section, below the first one, we see a red poppy field, guarded by an Afghan man dressed in a green military uniform holding a machine gun with his hands. Two poppy pods block and stick out of the man's ears. Below the section is the caption Drug Control... To the right, below the second section, an Afghan man is sitting on a woman's body in a blue burka. A burka has a mesh through which a Muslim woman can see, but in the image there is a black void instead of eyes and the implication is that Afghan men not only deny women the right to talk, they deny them the right to look and see. The man's left arm is straight from the elbow, with a raised middle finger, implying that Afghan men have no intention of granting women equal rights. Below the section is the caption Equal Rights...

Incongruities and cartoon interpretation. The cartoon is easy to comprehend in the sense that it is easy to get the cartoonist's message as a result of the interaction between images, title and captions. It reveals the gap between official propaganda and reality. As expected, in each section there has to be at least one incongruity. The incongruity is triggered by the interaction between each of the images and the caption under the images. The captions present the claims made by Britain and the other countries involved in the conflict that they would bring democracy, but the messages the images evoke deny the claims in the captions. We understand elections in Afghanistan are rigged, farmers continue to grow poppies for opium production, discrimination against women and girls continues and there is still violence and insecurity. The interaction between the Democracy, Security and Equal Rights captions and respective image triggers the Logical Mechanism juxtaposition and the interaction between the Drug Control caption and image triggers the Logical Mechanism of role reversal: it's not the countries bringing democracy to Afghanistan that control poppy growing and opium production; rather, it's the Taliban that guard poppy fields and produce opium. There is another incongruity in the form of a visual metaphor in the Drug Control image: the two poppy pods sticking out of the man's ears implying the man is deaf to the expectation not to grow poppies.

In jokes, in addition to the foregrounded or focal incongruity in the punchline, there are completely backgrounded and backgrounded incongruities in the set-up part some of which are not relevant for the joke, yet others enable the resolution of the foregrounded or focal incongruity in the punchline (Attardo et al. 2002, Hempelmann \& Attardo 2011). The visual metaphor in the Drug Control image of poppy pods sticking out of the man's ears has the 
status of a backgrounded incongruity that has no bearing on the evocation of the Logical Mechanism role reversal, yet it conveys a message that reinforces the role reversal. The juxtaposition and the role reversal Logical Mechanisms are fully resolved in the interaction between image and caption. The four images and captions in the cartoon might evoke a broader context dependent upon the interpreter's beliefs and assumptions about the world in line with general cognitive inferential principles.

The cartoonist's message to the viewer/reader. Viewers/readers are not to trust politicians blindly.

The next political cartoon ${ }^{5}$ is by Dave Brown, published in the Independent, November 28 , 2013. It has no title or caption(s).

Visual context in the cartoon. In the foreground we see three men. The one on the left has the Romanian national flag on his back and the man to the right, wearing a black moustache, is covered with the Bulgarian national flag. In the middle is David Cameron, the former British Prime Minister, holding the British national flag in his right hand. With his right leg he is pushing the Romanian in the back and is stretching his left arm and hand against the Bulgarian who is about to fall to the ground staggering on his left foot. In the background, following David Cameron in a car, recognizable as Bentley, is Nigel Farage, the then leader of the United Kingdom Independence Party, smoking a cigarette. The Bentley is in yellow and purple, the two colours on the party's logo and the abbreviation of the party UKIP is on the car's number plate.

Incongruity and cartoon interpretation. Although Dave Brown's political cartoon has no title or caption(s), the viewer has no difficulty in working out what the cartoon is about: David Cameron's and Nigel Farage's position to job seekers from EU member states from Eastern Europe. The cartoon abounds in visual metonymies - the three national flags stand for Great Britain, Bulgaria and Romania, respectively. There are four other visual metonymies: former Prime Minister David Cameron representing the country and the Conservative Party, Nigel Farage standing for the United Kingdom Independence Party and the two men standing for Bulgaria and Romania. There is also the visual representation of the conventional verbal metaphor to kick somebody out-David Cameron kicking a Romanian job seeker. The incongruity in the visual representation of to kick somebody out is strengthened by the visual metonymy PERSON FOR COUNTRY. The incongruity serves as a tool for the introduction of the Logical Mechanism exaggeration: the power of the Prime Minister is exaggerated in his attempt to stop job seekers from Eastern Europe. As in other political cartoons, David Cameron is painted as a gentleman and in cartoons Nigel Farage either smokes a cigarette, a cigar and/or drinks beer.

The cartoonist's message to the viewer/reader. It is beyond the power of a prime minister or a party leader to stop job seekers from Eastern Europe. 


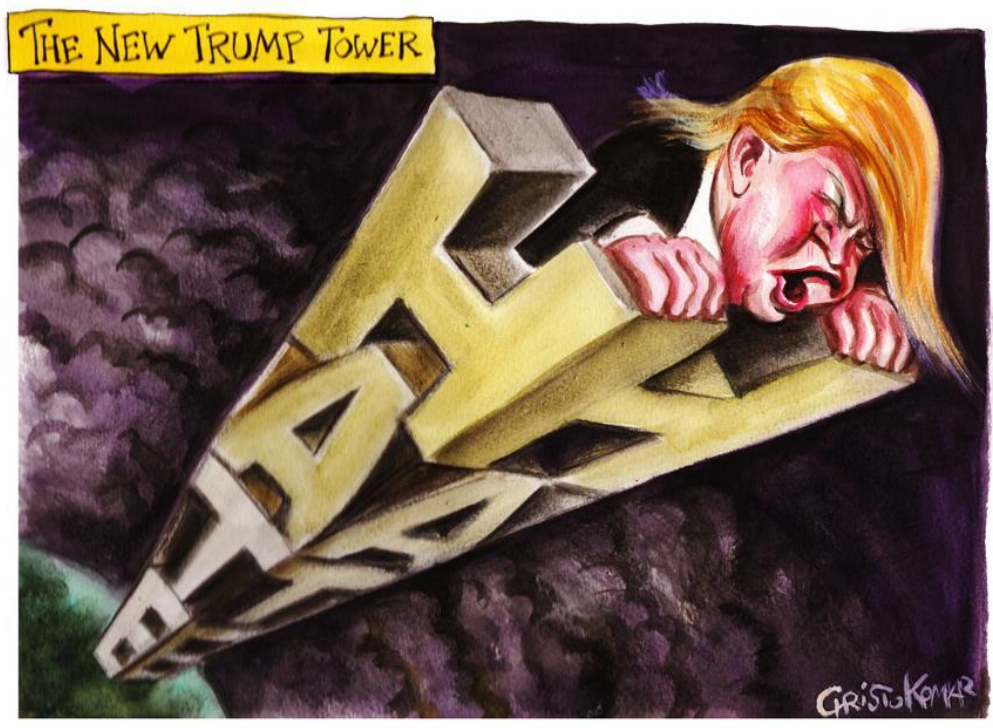

Figure 1. Political cartoon by Christo Komarnitski, reproduced by permission of the artist

Visual and verbal context in the cartoon in Figure 1. The cartoon is about Trump's presidential campaign in 2016 and has the title The New Trump Tower. In the cartoon, diagonally, from left to right, we see a tower made out of large letters that read Hate. The tower, sticking up from the Globe, is in reverse perspective and on its top we see Donald Trump's head with a long forelock of fair hair all the way down the left side of his face. He is clutching the tower with his hands, his mouth is wide open as if speaking in a loud voice to imaginary voters. His eyes are closed. The background is dark, making Trump's body indistinct.

Incongruities and cartoon interpretation. The cartoon is a reinterpretation of Trump's Tower, the 58-story mixed-use skyscraper on Fifth Avenue in New York. The first incongruity is between Trump's Tower in New York and the tower made out of letters in the cartoon. The second incongruity is between a 'normal' tower of the letters Hate, with wide foundations and narrow top, and the tower in reverse perspective in the cartoon. The tower and Trump trigger the conceptual metaphor TRUMP'S SPEECH FOSTERS HATE, in which both target and source are visually expressed and which matches best the cartoonist's message. The metaphor is strengthened by the visual metonymy PERSON FOR COUNTRY. The two incongruities trigger the Logical Mechanism analogy that is partially resolved.

The cartoonist's message to the viewer/reader. Trump's speech fosters hate.

The political cartoon by Patrick Chappatte ${ }^{6}$ appeared in the International New York Times, June 23, 2016. It has no title, but it has captions.

Visual and verbal context in the cartoon. Most of the space in the cartoon is taken up by the image of the globe with the map of the United Kingdom. Northern Ireland, which is a part of the United Kingdom, is not marked on the Globe. To the right of the map of the United Kingdom the viewer imagines the missing map of Europe. High above the island one sees the United Kingdom's national flag, waving in the air. Lower than the flag in large letters is a pennant, which reads Free at last. To the left of the pennant are the two small figures of a woman and a man. In his left hand the man has an umbrella, an indispensable commodity in the life of an Englishman. To the left of the map of the United Kingdom, in a white circle, one reads the question: Who are we going to blame for our problems now? The word blame is written in larger letters.

Incongruities and cartoon interpretation. There are two visual metonymies in the cartoon: the map standing for the United Kingdom and the woman and man standing for the country, 
evoking the conceptual metonymy PERSON FOR COUNTRY. In the cartoon, the first visual incongruity is between the United Kingdom after Brexit and the rest of the world that is not represented on the globe. The United Kingdom being the only country in the world is an exaggeration, of course, but it matches the beliefs of those who voted 'yes' in the referendum not to be a member of the EU Common Market and not to comply with the EU social and economic policies. There is a second incongruity, the visual metaphor FREEDOM IS ISOLATION, as a result of the interaction between the caption Free at last and the image of the United Kingdom as the only country on the Globe. In the metaphor only the target is visually expressed through the adjective free, while the source is inferentially arrived at. The other caption Who are we going to blame for our problems now? is a question yes-Brexit voters are yet not aware of, but they will inevitably ask. Yes-voters will, most likely, mean it literally, but the cartoonist has rather used it ironically and the prototypical use of irony is ironic criticism (Schwoebel et al. 2007). Since ironic utterances have only a pragmatic and not a semantic interpretation (Carston and Wearing 2015), the speaker's major goal in the use of an ironic utterance is the communication of attitude rather than the communication of specific propositional content. There are two visual metonymies in the cartoon: the map standing for the United Kingdom and the man and the woman standing for the country. The FREEDOM IS ISOLATION metaphor matches best the cartoonist's communicative goal. The image of the United Kingdom as the only country in the world and the conceptual metaphor FREEDOM IS ISOLATION serve as a tool for the introduction of the Logical Mechanism exaggeration that partially resolves the incongruity.

The cartoonist's message to the viewer/reader. The UK citizens have made the wrong choice.

Bruce MacKinnon's cartoon ${ }^{7}$ from The Chronicle Herald, March 17, 2016 has no title and caption(s).

Visual and verbal context in the cartoon. In the foreground of the cartoon we see a podium with the inscription Trump 2016. The inscription tells us that the man behind the podium is Donald Trump. He has an open petrol can and funnel for head (we assume the can is full of petrol). Trump is surrounded by matchsticks with huge red phosphorus heads. The viewer deduces that, most likely, the matchsticks are Trump's white electorate in small towns and rural areas who see immigrants and ethnic minorities as a threat. Perhaps his speech is racist, sexist and xenophobic; the media have published a long list of such statements. One spark is enough to start an explosion and the spark is Trump's speech.

Incongruities and cartoon interpretation. In the cartoon, what presumably attracts the interpreter's attention is a visual incongruity in the form of the visual metaphor TRUMP'S HEAD IS A PETROL CAN, in which both target and source are visually expressed. There is a second visual incongruity in the form of the visual metaphor DONALD TRUMP'S SUPPORTERS ARE MATCHSTICKS in which only the source MATCHSTICKS is visually conveyed. Since we do not have the cartoonist's comments on his motivation in painting the cartoon, its interpretation beyond the images is a probabilistic one and is built upon one's knowledge about Trump and his presidential campaign. The two metaphors trigger the inferential conceptual metaphor FIRE IS DESTRUCTION. Trump's opponents see him and his electorate as a threat to the country is a justifiable implication inferred from the images. The two visual metaphors evoke the same conceptual metaphor, namely, A COUNTY IS A PERSON. The two visual metaphors are perceived as salient or foregrounded and focal. They enable inferentially the introduction of the Logical Mechanism juxtaposition between Trump and his supporters, on the one hand, and voters that disapprove of Trump and his presidential campaign, on the other, that are not represented in the cartoon. The Logical Mechanism partially resolves the incongruity. 
The cartoonist's messages to the viewer/reader. Trump's inflammatory rhetoric is likely to result in a conflagration.

Dave Brown's political cartoon ${ }^{8}$ was published in the Independent, August 13, 2013. The cartoon has captions.

Visual and verbal context in the cartoon. In the foreground we see a transparent plastic package with four naked dead men with their mouth open. The bodies are arranged head to feet to save space. The men are to be sold as pieces of meat at the supermarket. In the middle of the package there are three inscriptions against blue background one below the other. The first is in largest letters and reads: Migrant Workers. Below, in smaller letters, we read: Cheap Labour Value Pack followed below by Produce of Eastern Europe. To the right of the three inscriptions, in a red circle is written: 2 for the price of one! In the lower right corner of the cartoon in big red letters one reads TESKO and below it it reads: Every Lithuanian helps, a modification of Teskos' slogan Every little helps. The package and the Tesko inscription are against pale yellow background.

Incongruities and cartoon interpretation. Dave Brown's cartoon is about Tesko's employment of migrant workers from low-wage EU countries and not paying them the national minimum wage it has to pay if it employed local workers. The cartoonist's motivation in painting the cartoon is to expose Tesko's exploitation of such workers. There is a visual incongruity between the four asphyxiated naked human bodies and the food packet they are packed into to be sold by Tesko as dead meat. The pictorial representation evokes the conceptual metaphor THE HUMAN BODY IS A COMMODITY whose target and source are visually presented. There is a second incongruity in the cartoon: an incongruous fusion in the captions Migrant Workers, Cheap Labour Value Pack and Produce of Eastern Europe in different letter size of two different contexts-Tesko's employment of cheap labour and food advertisements. There is a third incongruity between Tesko's slogan Every little helps and its modification Every Lithuanian helps. The most probable inference the cartoon evokes beyond the visual incongruity and the verbal incongruities in the captions is the following: Cheap food comes from cheap labour. The cartoon criticizes Tesko's (and UK's) employment policies yet Lithuanians might assume they are the ones that are the target of the cartoon and find it racist and offensive. And indeed they did. A response followed from the then Lithuanian ambassador to the UK who wrote a letter to the Independent saying the cartoon was "despicable, tasteless, racist and xenophobic." 9 The foregrounded visual metaphor THE HUMAN BODY IS A COMMODITY and the foregrounded verbal incongruity in the captions between Tesko's cheap labour employment policy and food advertising enable the Logical Mechanism juxtaposition that partially resolves the incongruities.

The cartoon is a disturbing and not a funny one. It was rated as unfunny by 12 second year BA students studying English language and literature. Why isn't the cartoon funny in spite of the Logical Mechanism? First, because of misinterpretation of the cartoonist's targetTesko's employment of cheap labour and not Lithuanian workers. And, second, the interpreter's not distancing enough from the images of asphyxiated men: after all, the cartoon is not a direct representation of an existing state of affairs.

The cartoonist's message to the viewer/reader. The cartoonist disapproves of Tesko's treatment of migrant workers from low-wage EU countries.

Peter Brookes's political cartoon ${ }^{10}$, entitled America's Gothic Horror, appeared in The Times, March 3, 2016.

Visual and verbal context in the cartoon. In the foreground we see two bodies: Donald Trump's robust body down to the waist and the smallish figure of a woman on his left farther back. Trump is wearing a white shirt and dark blue jacket. In his right hand he is holding a metal fork whose three tines reach his shoulders. His mouth is open, leaving the impression that he is addressing an audience. His fair hair is in the shape of a haystack half the size of his 
face. The woman is in period clothes from before World War II, eyes wide open and directed towards Trump. She has covered her ears with her hands and her mouth is wide open, too. In the background we see a one-floor house with a porch and a Gothic window in the attic.

Incongruities and cartoon interpretation. The cartoon is a parody of two famous works of art. Typically, the function of parody is to imitate, distort, reinterpret or criticise individuals or prior texts (verbal and non-verbal) in order to achieve a humorous effect. In political cartoons, when referring to a well-known work of art, the cartoonist doesn't regard it as the object of parody, rather he uses it as a point of departure to direct his/her disapproval or criticism of a politician. In such cartoons, the cartoonist is playing with art, the primary function of parody as a technique (Chambers 2010) to achieve his/her communicative goal. Peter Brookes's political cartoon is a hybrid of Grant Wood's painting American Gothic and Edvard Munch's The Scream mentioned in the cartoon by the cartoonist himself. In the cartoon, the farmer from Wood's painting is replaced by Trump and the sexless figure from Munch's painting, screaming in horror, is the wife (or daughter) in the cartoon's context of American Gothic. In the new context, the facial expression of the wife is that of astonishment and disbelief of Trump's rants during his election campaign. The pictorial representation of the two figures reinforces the cartoon's title America's Gothic Horror: in the title American from Wood's painting is transformed into America and the verbal hybrid of American Gothic and Horror is added as the most likely response to Munch's painting. In the original painting Gothic can be ambiguously interpreted between Gothic in relation to architecture and Gothic meaning portentously gloomy or horrifying. In the cartoon, the architecture related meaning is left out. The title explicitly states the cartoonist's message that Trump's prospective presidency would be horrifying. The parodic representation triggers an incongruity between the purpose of a work of art - to evoke aesthetic appreciation - and the non-aesthetic end to which it is used in the cartoon-to criticise a politician. Trump's image evokes the conceptual metonymy PERSON FOR COUNTRY. The parodic representation introduces the Logical Mechanism of parallelism that partially resolves the incongruity.

The cartoonist's message to the viewer/reader. Trump's presidency would be horrifying.

Dave Brown's political cartoon ${ }^{11}$, entitled Time Gentlemen Please... appeared in the Independent, July 5, 2016.

Visual and verbal context in the cartoon. In the foreground we see a big puddle of spilt beer in the street, near the curb of the pavement. The spilt beer resembles a human face: it has two small white beer bubbles for eyes, another bubble below shapes the nose and, below the nose, where we expect to see the mouth, is a dead cigarette butt surrounded by small beer rings. Part of the chin is flowing into the metal grate of a rainwater collector. A few wavelike lines resemble wrinkles on the forehead. Above the forehead, beer foam shapes a forelock of hair. In the left upper corner, where the forehead ends, is a fallen empty beer glass.

Incongruities and cartoon interpretation. Undoubtedly, the political cartoon by Dave Brown poses greater comprehension challenges compared to the ones above. The viewer will be able to comprehend the cartoon if he/she has read the Independent editorial for the day and if the editorial is about Nigel Farage's resignation as Ukip leader after the Brexit referendum. Only then will he/she be able to work out that the face-like image of spilt beer is Farage's. The title Time Gentlemen Please... makes a reference to a British TV sitcom from 2000 to 2002 set in a provincial pub. The pub owner is right-wing and has old-fashioned ideas about British politics that he flaunts about in the sitcom. The title also reads literally and reminds drinkers in the pub to leave the premises. The beer is spilt on the street and usually one spills beer when he/she is not careful enough or when he/she is drunk - a reference to Nigel Farage's drinking habits. His spilt-beer image is dripping into the sewer implying that his political career is over. The image of the mouth used as an ashtray triggers the conceptual metaphor A MOUTH IS AN ASHTRAY, in which there is a fusion of target and source. The spilt-beer face is a PART 
FOR WHOLE visual metonymy for Nigel Farage. In this political cartoon there are three incongruities: first, the conceptual metaphor, second, the TV sitcom context versus the pub context and Nigel Farage stepping down as Ukip leader versus his drinking habits. In political cartoons, as with the setup part of jokes, there is also a level of reinterpretation, most often it is the reinterpretation of the banal and the cliché. Here, the reinterpretation of the sitcom and the pub context. The focal visual incongruity of the spilt-beer face introduces the Logical Mechanism analogy that is partially resolved.

The cartoonist's message to the viewer/reader. Nigel Farage's political career is over.

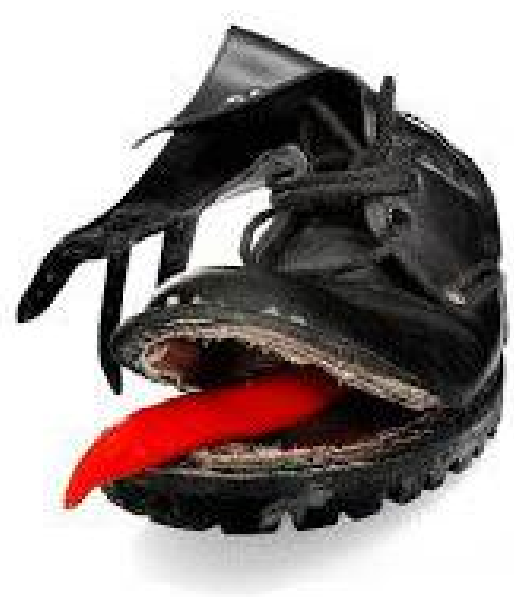

Figure 2. A photo from Roman Montesinos's photography exhibition at the House of Humour and Satire in Gabrovo, Bulgaria. Reproduced with permission of the photographer.

Indeed, an incongruity is a prerequisite for humour, but it is not enough. In Figure 2 there is a visual incongruity in the form of a visual metaphor, but the incongruity is not funny, since no humour technique or Logical Mechanism has been used to (partially) resolve the incongruity. Excluding the two weak metaphors A TIE IS A TONGUE and A SHOE CAP IS A MOUTH, there is no additional visual and background context to strengthen the visual incongruity (the only context at the exhibition is the frame of the photograph). On the other hand, in real life there could be an incongruous situation that involves a Logical Mechanism found in jokes, for example, a figure-ground reversal, as in the following insurance claim for a car accident (characterised as funny on the internet): In my attempt to kill a fly, I drove into a telephone pole. $^{12}$ The incongruity is between the attempt to kill a fly and hitting a telephone pole, but it is not perceived as funny by the people involved at the time the accident occurred in spite of the intrinsic incongruity and the humour technique; it only becomes funny when they distance themselves from the situation and adopt a humorous attitude towards the incongruity.

\section{Conclusion}

In the article, the concept of incongruity was used not only as the prerequisite for humour, but as a common denominator for verbal and visual metaphors as well. Verbal and visual metaphors and metonymies in the political cartoons studied were analysed from the point of view of Conceptual Metaphor and Metonymy Theory. Visual metaphors, visual metonymies and visual parody in the cartoons serve as a tool for the introduction of a Logical Mechanism 
from the GTVH in one-panel cartoons. Two, three and four Logical Mechanisms are evoked in two-, three- and four-panel cartoons, respectively. In addition of being enablers of a Logical Mechanism, visual incongruities can reinforce the verbal message in the title and/or caption(s). Pictorial representations and inferential conceptual metaphors triggered by the cartoon can reinforce the respective Logical Mechanism. There is a marked difference between humour in jokes and political cartoons as far as incongruities are concerned. In jokes there is only one foregrounded incongruity introduced in the punchline, whereas in political cartoons there could be more than one enabling the introduction of a Logical Mechanism: it can be a visual metaphor or the result of the interaction between an image and a title or an image and a caption. The images, title and captions (whenever any) evoke interpretations that are dependent on the viewer/reader's knowledge of the event or situation the cartoonist is representing. And, more generally, on the interpreter's education, interest and familiarity with the genre. By presumption, the viewer/reader is expected to be as well-informed and educated as the cartoonist himself/herself. Humour in political cartoons is not an end in itself: it facilitates the cartoonist's communicative goal to expose and criticise, implicitly and explicitly, the foibles of political, economic and military elites such as arrogance of power, incompetence and corruption. Undoubtedly, further research on humour in political cartoons (and cartoons) is needed to capture the complexity and interplay between the two modes of communicationnonverbal and verbal.

\section{Notes}

1 https://www.theatlantic.com/politics/archive/2014/09/legendary-cartoonist-pat-oliphantwe-are-in-a-forest-fire-of-ignorance/379524/ (Accessed on March 6 2017)

$2 \mathrm{http}: / / \mathrm{www} .0$ riginal-political-cartoon.com/cartoon-history/we-cartoonists-are-trueoutsiders-journalism/ (Accessed on March 6 2017)

3 https://www.quora.com/Are-most-political-cartoons-intended-to-be-funny (Accessed on March 6 2017)

4 http://www.rawa.org/temp/runews/2009/10/06/human-development-report-2009-factsheetafghanistan-ranked-181-out-of-182-countries.phtml (Accessed on October 7 2017)

$5 \mathrm{http}: / /$ www.voxeurop.eu/en/content/cartoon/4361241-make-way (Accessed on Oct. 72017 )

6 http://theweek.com/cartoons/632237 (Accessed on October 7 2017)

7 https://www.pinterest.com/pin/319826011018758429/ (Accessed on October 7 2017)

8 https://lenta.ru/news/2013/08/14/lithuania/ (Accessed on October 7 2017)

9 http://bnn-news.com/lietuviesi-sasutusi-par-aizskarosu-karikaturu-britu-laikraksta-101469 (Accessed on March 6 2017)

10 https://www.thetimes.co.uk/article/peter-brookes-cartoon-s00znkxr2 (Accessed on October 7 2017)

11 http://www.ellwoodatfieldgallery.com/ (Accessed on October 7 2017)

$12 \mathrm{https} / / \mathrm{www} \cdot$ google.bg/search?dcr=0\&biw=1280\&bih=900\&tbm=isch\&sa=1\&ei=rZm3W oS_JouckgWcgZKgCA\&q=political+cartoons+Dave+brown+Tme+gentlemen $\% 2 \mathrm{C}+$ please \&oq=political+cartoons+Dave+brown+Tme+gentlemen $\% 2 \mathrm{C}+$ please\&gs_l=psyab.3...15068.25430.0.25770.33.33.0.0.0.0.112.2892.29j4.33.0...0...1c.1.64.psyab..0.0.0....0.IQFe_C3Y-Aw (Accessed on March 25 2018)

\section{References}

Attardo, S. (1997). 'The semantic foundations of the cognitive theories of humor'. Humor: International Journal of Humor Research 10 (4), pp. 395-420. 
Attardo, S. (2001). Humorous Texts: A Semantic and Pragmatic Analysis. Berlin, New York: Mouton de Gruyter.

Attardo, S. \& Raskin, V. (1991). 'Script theory revis(it)ed: Joke similarity and joke representation model'. Humor: International Journal of Humor Research 4 (3-4), pp. 223 347.

Attardo, S., Hempelmann, Ch. F. \& Maio, S. (2002). 'Script oppositions and logical mechanisms: Modeling incongruities and their resolutions'. Humor: International Journal of Humor Research 15 (1), pp. 3-46.

Cagle, D. \& Fairrington, B. (eds.). (2007). The Best Political Cartoons of the Year 2007. Cagle Cartoons, Inc.

Carston, R. \& Wearing, C. (2015). 'Hyperbolic language and its relation to metaphor and irony'. Journal of Pragmatics 79, pp. 79-92.

Chambers, R. (2010). Parody: The Art that Plays with Art. Frankfurt: Peter Lang.

El Refaie, E. (2003). 'Understanding visual metaphor: the example of newspaper cartoons'. Visual Communication 2, pp. 75-95.

El Refaie, E. (2014). 'Reconsidering 'image metaphor' in the light of perceptual simulation theory'. Metaphor and Symbol 30 (1), pp. 63-76.

Forceville, Ch. (2002). 'The identification of target and source in pictorial metaphors'. Journal of Pragmatics 34, pp. 1-14.

Genova, D. (2011). Studying Humour Seriously. Veliko Turnovo: Faber.

Gombrich, E. H. (1971). 'The cartoonist's armoury', in Gombrich, E. H. Meditations on a Hobby Horse and Other Essays on the Theory of Art, London: Phaidon, pp. 127-142.

Grady, Ch. L., McIntosh, A. R., Rajah, N. \& Craik, F. I. M. (1998). 'Neural correlates of the episodic encoding of pictures and words'. Proceedings of the National Academy of Sciences, vol. 25, pp. 2703-2708.

Hempelmann, Ch. F. \& Sampson, A. C. (2008). 'Cartoons: Drawn jokes?', in Raskin, V. (ed.). The Primer of Humor Research, Mouton de Gruyter, pp. 609-640.

Hempelmann, Ch. F. \& Attardo, S. (2011). 'Resolutions and their incongruities: Further thoughts on Logical Mechanisms'. Humor: International Journal of Humor Research 24 (2), pp. 125-149.

Kennedy, J. M., Green, Ch. D. \& Vervaeke, J. (1993). 'Metaphoric thought and devices in pictures'. Metaphor and Symbolic Activity 8 (3), pp. 243-255.

Kittay, E. (1990). Metaphor: Its Cognitive Force and Linguistic Structure. Oxford: Oxford University Press.

Kuipers, G. (2006). Good Humour, Bad Joke: A Sociology of the Joke. Berlin and New York: Mouton de Gruyter.

Lakoff, G. \& Johnson, M. (1980). Metaphors We Live By. Chicago: University of Chicago Press.

Lakoff, G. (1987). Women, Fire and Dangerous Things: What Categories Reveal about the Mind. Chicago: University of Chicago Press.

McGhee, P., Ruch, W. \& Hehl, F. (1990). 'A personality-based model of humor development during adulthood'. Humor: International Journal of Humor Research 3, pp. 119-146.

Nilsen, A. P. \& Nilsen, D. L. F. (2000). Encyclopedia of $20^{\text {th }}$ Century American Humor. Phoenix, Arizona: Oryx Press.

Oring, E. (2003). Engaging Humor. Urbana and Chicago: University of Illinois Press.

Samson, A. C. \& Huber, O. (2007). 'The interaction of cartoonist's gender and formal features of cartoons'. Humor: International Journal of Humor Research 20, pp. 1-25.

Schwoebel, J., Dews, Sh., Winner, E. \& Srinivas, K. (2007). 'Obligatory processing of the literal meaning of ironic utterances: Further evidence', in Gibbs, R. W. \& Colston, H. L. 
(eds.), Irony in Language and Thought: A cognitive science reader, London: Routledge, pp. 253-268.

Shultz, Th. R. (1976). 'A cognitive-developmental analysis of humour', in Chapman, A. J. \& Foot, H. (eds.) Humour and Laughter: Theory, research and applications, London and New York: John Wiley and Sons, pp. 11-36.

Steen, G. (2007). Finding Metaphor in Grammar and Usage: A Methodological Analysis of Theory and Research. Amsterdam/Philadelphia: John Benjamins Publishing Company.

Suls, J. M. (1972). 'A two-stage model for the appreciation of jokes and cartoons', in Goldstein, J. H. \&, McGhee, P. E. (eds.) The Psychology of Humour, New York: Academic Press, pp. 41-45.

Suls, J. M. (1983). 'Cognitive processes in humour appreciation', in McGhee, P. E. \& Goldstein, J. H. (eds.) Handbook of Humour Research. New York: Academic Press, pp. 39-57.

Tsakona, V. (2009). 'Language and image interaction in cartoons: Towards a multimodal theory of humor'. Journal of Pragmatics 41, pp. 1171-1188. 